\title{
Primeiros dados quali-quantitativos do mexilhão-dourado, Limnoperna fortunei (Dunker), no Delta do Jacuí, no Lago Guaíba e na Laguna dos Patos, Rio Grande do Sul, Brasil e alguns aspectos de sua invasão no novo ambiente ${ }^{1}$
}

\author{
Maria Cristina Dreher Mansur 2, Cíntia Pinheiro dos Santos 2, Gustavo Darrigran 3, Ingrid \\ Heydrich ${ }^{4}$, Claudia T. Callil ${ }^{2} \&$ Felipe Rossoni Cardoso ${ }^{2}$
}

\author{
${ }^{1}$ Trabalho realizado em parte com auxílio da Fundação Antorchas (cooperação Brasil-Chile-Argentina) e parte pelo \\ Programa Pró-Guaíba, Rio Grande do Sul, Brasil. \\ ${ }^{2}$ Museu de Ciências e Tecnologia, PUCRS. Avenida Ipiranga 6681, 90619-900 Porto Alegre, Rio Grande do Sul, Brasil. \\ E-mail: momansur@pucrs.br \\ ${ }^{3}$ Facultad Ciencias Naturales y Museo (UNLP). Paseo Del Bosque, 1900 La Plata, BA, Argentina. \\ E-mail: invasion@way.com.ar \\ ${ }^{4}$ Museu de Ciências Naturais, Fundação Zoobotânica do Rio Grande do Sul. Rua Doutor Salvador França 1427, \\ 90690-000 Porto Alegre, Rio Grande do Sul, Brasil.E-mail: ingridh@cpovo.net
}

\begin{abstract}
Quali-quantitative first data of golden mussel, Limnoperna fortunei (Dunker), in Jacuí Delta, Guaíba Lake and Patos Lagoon and some invasion aspects. At the end of 1998 and the beginning of 1999, the golden mussel Limnoperna fortunei (Dunker, 1857), Mytilidae, originating from Southeast Asia, was registered for the first time in the Guaíba Lake Basin, Rio Grande do Sul State, Brazil. Quantitative samples were taken since the first register and for two years at various localities in the Jacuí Delta, northern limit of Guaíba Lake, and in the south limit of the later where it empties into Patos Lagoon. Samplings in Patos Lagoon revealed the presence of L. fortunei in October 2000 at Arambaré $\left(30^{\circ} 54^{\prime} \mathrm{S}, 51^{\circ} 30^{\prime} \mathrm{W}\right)$ and in January 2001 at São Lourenço do Sul $\left(31^{\circ} 20^{\prime} \mathrm{S}, 51^{\circ} 58^{\prime} \mathrm{W}\right)$. Quantitative samplings on roots of water hyacinths Eichhornia azurea (Sw.) Kunth and E. crassipes (Mart.) Solms-Laubach, on rhizomes of rushes Scirpus californicus (C.A. Mey.) Steud. and on trunks of Cephalanthus glabratus (Spreng.) K. Schum, were made in Jacuí Delta and on the beaches of Vila de Itapuã and Pombas camping area, in the Municipality of Viamão. Limnoperna fortunei encreased in number to a maximum density of 27,275 individuals $/ \mathrm{m}^{2}$ one year and five months after the first register and 62,100 individuals $/ \mathrm{m}^{2}$ two years later. In November 2000, i.e., two years after the appearance of the species in Guaíba Lake, it was recorded the first macrofouling in the pipes catching water for the city of Porto Alegre and in filters and pipelines of the cellulose industry Riocell-Klabin, Municipality of Guaíba $\left(30^{\circ} 06^{\prime} \mathrm{S}, 51^{\circ} 20^{\prime} \mathrm{W}\right)$. Limnoperna fortunei preferentially occur on rhizomes of rushes, initially forming flat clusters that grow to large mass. It also fix on the shells and soft parts of native bivalves and on shells and operculum of gastropods, prevening full closure of these mollusks. The recent decrease of rushy areas on the shores of Guaíba Lake is attributed to invasion of $L$. fortunei.
\end{abstract}

KEY WORDS. Macrofouling, Mytilidae, population density, South Brazil, substratum preferences.

Até a década de 1970 a fauna de bivalves da Bacia da Laguna dos Patos consistia aproximadamente de 25 espécies de Unionoida (Hyriidae e Mycetopodidae) (MANsur 1970, BonetTo \& Mansur 1970, Mansur \& Garces 1988, Mansur et al. 1994), quatro de Sphaeriidae (Pereira et al. 2000) e de um único Corbiculidae: Neocorbicula limosa (Maton, 1811). Segundo Parodiz \& Hennings (1965), esta espécie seria endêmica das bacias hidrográficas do sul do Brasil e dos rios Paraná, Paraguai e Uruguai.
VeITENHEIMER-MENDES (1981) registrou pela primeira vez para a Bacia do Lago Guaíba, sul do Brasil, um Corbiculidae originário do sudeste asiático. Na época foi identificado como Corbicula manilensis (Philippi, 1884), sinônimo júnior de $C$. fluminea (Müller, 1774) conforme MorTon (1979). De acordo com o ano de coleta e tamanho dos espécimes, a autora estimou que esse bivalve asiático teria sido introduzido nesse manancial, no início da década de 1970 . A introdução não teria sido intencional, mas provavelmente com água de lastro de 
embarcações, uma vez que foi coletada pela primeira vez, nesse mesmo ano (ITUARTE 1981), em localidades próximas aos portos de Porto Alegre, sul do Brasil, e de Buenos Aires, Argentina. Essa espécie vem se propagando gradativamente pelas bacias dos rios Paraná e Uruguai (ItUARTe 1994) e mais recentemente atingiu as nascentes do alto Rio Paraguai, Brasil (CAllil \& Mansur 2002).

Mansur et al. (1999) constataram, no início desse ano, a presença na Bacia do Lago Guaíba, do Mytilidae Limnoperna fortunei (Dunker, 1857), conhecido como mexilhão-dourado, também originário do sudeste da Ásia.

Segundo PASTORINo et al. (1993), o primeiro registro desta espécie para a América do Sul foi no Rio da Prata, balneário de Bagliardi $\left(34^{\circ} 55^{\prime} \mathrm{S}, 57^{\circ} 59^{\prime} \mathrm{W}\right)$, próximo de Buenos Aires, Argentina, em 1991. A introdução teria ocorrido com água de lastro de navios do sudeste da Ásia (Coréia e China), uma vez que a época do aparecimento da espécie na Argentina coincidiu com os picos mais altos de intercâmbio comercial entre aqueles países (Darrigran \& Pastorino 1995). Segundo Darrigran (2000), $\mathrm{o}$ alto poder reprodutivo e a falta de inimigos naturais, propicia ao mexilhão-dourado a formação de grandes aglomerados, causando macrofouling. Este último reduz a passagem no interior das tubulações, com decréscimo de velocidade do fluxo da água por fricção, causa entupimentos nos sistemas coletores de água pelo acúmulo de conchas vazias e também a contaminação da água pela mortandade e deterioração em massa. Esses fatores causam ainda a oclusão de bombas, filtros e sistemas de refrigeração de indústrias. DARRIGRAN (1995) cita o primeiro caso de macrofouling em água doce na América do Sul, em locais de captação de água para consumo humano no Rio da Prata, Argentina $\left(34^{\circ} 55^{\prime} \mathrm{S}, 57^{\circ} 59^{\prime} \mathrm{W}\right)$. No ambiente natural, $L$. fortunei altera a composição do bentos, favorecendo o aparecimento de certos invertebrados em detrimento de outros (DARRIGRAN $e t$ al. 1998).

DARRIGRAN \& PASTORINO (1993) registraram para a localidade de Bagliardi a densidade de 31.222 ind. $/ \mathrm{m}^{2}$ de $L$. fortunei em 1992, e de 82.151 ind./m² em 1993. Neste mesmo ano a espécie já havia se dispersado por toda a margem direita do Rio da Prata, de Buenos Aires até Punta Piedras, Argentina. Em 1995 o mitilídeo foi encontrado também na margem esquerda do Rio da Prata, junto à cidade de Colônia, no Uruguai (SCARAbino \& VERDE 1994). Em 1995 e 1996 foi amostrado no Rio Paraná, em Santo Tomé, junto à cidade de Santa Fé, Argentina (DarRigran \& Ezcurra de Drago 2000a). Scarabino \& Masello (1996) encontraram L. fortunei aderido a raízes de juncos, no Rio Santa Lucia, perto de Montevidéu, Uruguai.

Limnoperna fortunei fixa-se a substratos firmes, causando danos por sufocamento aos bivalves nativos, em especial as Mycetopoda spp., tal o número de exemplares aderidos às conchas, inclusive às aberturas dos mesmos (DarRigran \& EzCURRA de Drago 2000b, Darrigran et al. 2000). O fenômeno é semelhante ao causado a bivalves nativos de água doce dos Estados Unidos, pelo mexilhão-zebra Dreissena polymorpha (Pallas, 1771), após a introdução acidental deste último naquele país (Neves et al. 1997). MANSUR et al. (1999) encontraram também $L$. fortunei sobre concha, próximo às aberturas inalante e exalante de Corbicula spp. e de Diplodon koseritzi (Clessin, 1888).

O presente estudo objetiva fornecer elementos básicos que permitirão monitorar a progressiva invasão do mexilhãodourado nos mananciais hídricos do sul do Brasil e registrar dados obtidos sobre a densidade populacional, danos à fauna nativa, ao ambiente e outros impactos inclusive de ordem econômica.

\section{MATERIAL E MÉTODOS}

\section{Área de estudo}

O estudo foi desenvolvido na região que compreende o Delta do Jacuí, o Lago Guaíba e a Laguna dos Patos (Fig. 1).

O Delta do Jacuí, situado ao norte e a montante do Lago Guaíba, é formado por um conjunto de oito ilhas grandes e várias pequenas. Na região deltaica desembocam os rios Gravataí, dos Sinos, Caí e Jacuí. Este último é o maior contribuinte em volume de água (84\%) e aporte de sedimentos, recebendo o delta o seu nome. Toda a região está sujeita a inundações periódicas. As margens das ilhas são em grande parte ocupadas pelo aguapé-de-baraço Eichhornia azurea (Sw.) Kunth e pelo aguapé flutuante E. crassipes (Mart.) Solms-Laubach.

O Lago Guaíba, com aproximadamente $500 \mathrm{~km}^{2}$, é alongado no sentido SE-NO, com cerca de $50 \mathrm{~km}$ de comprimento e $12 \mathrm{~km}$ de largura, em média. No leito existe um canal central de 5-6 $\mathrm{m}$ de profundidade, utilizado para a passagem de navios. A margem do lago constitui-se de uma seqüência de baías denominadas localmente de sacos, separadas por penínsulas geralmente formadas por morros graníticos e conhecidas como pontas ou pontais. Os sacos são rasos, com profundidades que raramente ultrapassam $2 \mathrm{~m}$. Uma área mais profunda, de 20 a $60 \mathrm{~m}$ situa-se ao sul do lago, próximo a sua desembocadura na Laguna dos Patos. As águas do Lago Guaíba dependem do regime de precipitação e não estão sob influência das marés. Nas enchentes o nível do lago pode alcançar a quota de $4 \mathrm{~m}$. A velocidade da corrente depende da intensidade dos ventos de NE e NO e também do fluxo de descarga dos distributários (VIERA \& RANGel 1988). As margens do Lago Guaíba são constituídas geralmente por praias arenosas com grandes áreas de juncais, onde se destaca Scirpus californicus (C. A. Mey.) Steud.

A Laguna dos Patos se comunica com o mar pelo extremo sul. Com aproximadamente $10.360 \mathrm{~km}^{2}$, drena o Lago Guaíba e uma série de rios circundantes. A penetração da cunha salina pelo canal de Rio Grande concorre para os índices de salinidade da laguna que variam ao longo do seu comprimento, conforme o regime de precipitação pluvial e freqüência dos ventos (VIERA \& RANGEL 1988). Influência esporádica de salinidade $(0,5 \%)$ pode chegar até a altura do Saco de Tapes (Schwarzbold et al. 1986, NiENCHESKI et al. 1988).

\section{Locais de amostragem e metodologia}

No Delta do Jacuí foram feitas coletas quantitativas em alguns canais, sacos, margens de ilhas e no canal da Companhia Petroquímica do Sul (COPESUL), no período de outubro de 1998 a janeiro de 2000 (Fig. 1). As coletas não foram realizadas nos mesmos pontos ao longo do período das amostragens. Em cada ponto recolheu-se amostras das raízes do aguapé-de-baraço (Eichhornia azurea) ou do aguapé flutuante (E. crassipes). As raízes foram triadas em laboratório segundo metodologia adaptada de Volkmer-Ribeiro et al. (1984). Os mexilhões foram fixados e conservados em álcool $70 \%$. As raízes foram secas em estufa e posteriormente pesadas, seguindo-se a quantificação dos indivíduos por grama de raiz. 


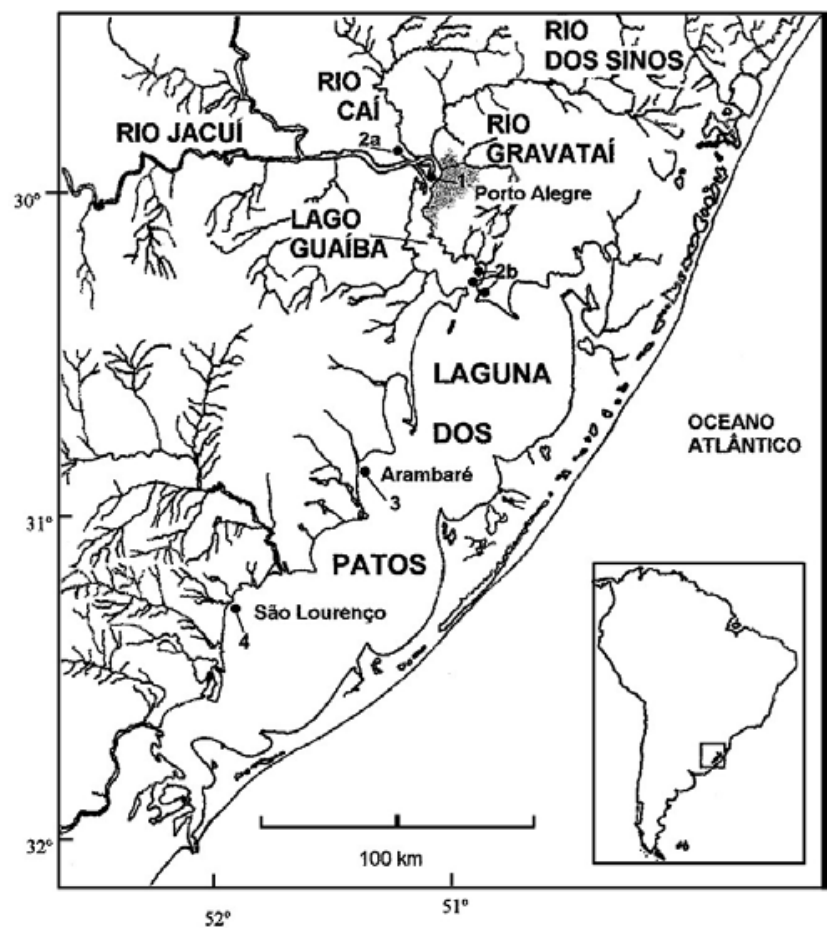

Figura 1. Mapa das localidades de amostragem no Delta do Jacuí, Lago Guaíba e Laguna dos Patos, Rio Grande do Sul, Brasil: (1) Ilha do Chico Inglês, em frente ao porto de Porto Alegre, localidade do primeiro registro de Limnoperna fortunei em 1998; (2) localidades do segundo registro, em 1999: (2a) canal da COPESUL, município de Triunfo, (2b) Vila de Itapuã, camping das Pombas e Praia da Pedreira, município de Viamão; (3) Arambaré, localidade do terceiro registro, em 2000; (4) desembocadura do Rio São Lourenço na Laguna dos Patos, localidade do quarto registro, em 2001.

No Lago Guaíba os locais de amostragem estão situados na margem esquerda do lago, nas praias arenosas da Vila de Itapuã, das Pombas (camping das Pombas) e da Pedreira, no município de Viamão (Fig. 1). Para coletas qualitativas, visitaram-se pontais, clubes náuticos, a Associação dos Pescadores da Praia do Veludo (APESCA), no município de Porto Alegre, para observação da fauna aderida a marinas, trapiches, barcos e instalações de captação de água e outros substratos firmes submersos ou rolados nas margens das praias arenosas. Aglomerados de L. fortunei foram detectados dentro d'água, tateando-se com os pés. Material retirado das bombas captadoras de água do Departamento Municipal de Águas e Esgotos de Porto Alegre (DMAE), foi cedido aos autores.

As coletas quantitativas foram feitas em rizomas de Scirpus californicus (C.A. Mey) Steud. (junco) e na Vila de Itapuã também em troncos de Cephalanthus glabratus (Spreng.) K. Schum. (sarandi).

Em rizomas, as coletas foram realizadas sempre nos mesmos pontos, ao sul do Lago Guaíba, de novembro de 1999 a dezembro de 2001. A profundidade de coleta nos juncais oscilou entre 50 a $110 \mathrm{~cm}$ abaixo da superfície da água. A temperatura do ar e da água foi medida a partir da coleta de 17.I.2001. Foram retirados aglomerados formados por $L$. fortunei, e a seguir fatiados em placas tridimensionais com base de $10 \times 10 \mathrm{~cm}$.

Nos troncos do sarandi, as amostragens estenderam-se de janeiro de 1999 a dezembro de 2000. Estes troncos oriundos de arbustos próximos à margem cortados e deixados dentro d'água entre os juncos pela comunidade local, apresentavam a superfície com algumas fissuras ou concavidades rasas, não sendo completamente lisos. Foram contados os indivíduos contidos em uma superfície de $20 \mathrm{~cm}$ de comprimento por 12 $\mathrm{cm}$ de largura.

Tijolos de cerâmica de 14 x 10,5 x 9,5 cm, vazados por seis perfurações de $3 \mathrm{~cm}$ e duas de $1 \mathrm{~cm}$ de diâmetro, foram colocados quinzenalmente e mensalmente, na periferia e dentro dos juncais para avaliação da incidência e do tempo de fixação de L. fortunei. Alguns permaneceram por um período mais longo correspondente a três, seis meses e um ano. Cada tijolo foi numerado e ancorado ao fundo, através de uma haste de ferro com $2 \mathrm{~m}$ de comprimento por $0,5 \mathrm{~cm}$ de diâmetro, transpassada por uma abertura de menor diâmetro do tijolo e enterrada no substrato numa profundidade aproximada de $50 \mathrm{~cm}$, permitindo estabilidade ao amostrador. A longa haste de ferro, em parte emersa, facilitou a localização do ponto exato de coleta dentro d'água, visto que permaneceram ao longo de todo o período de amostragem, sendo apenas os tijolos substituídos periodicamente.

No camping das Pombas, esses amostradores foram colocados junto à periferia do juncal, onde a lâmina d'água era mais profunda, demarcando seus limites em fins de 2000. Como as hastes de ferro permaneceram no local, foi possível dimensionar e calcular as perdas do mesmo, depois de passado um ano.

As amostras quantitativas foram imersas diretamente em álcool a $70 \%$ e os exemplares contados. Foram consideradas apenas as densidades máximas.

Os primeiros exemplares coletados no Delta do Jacuí e no Lago Guaíba foram medidos quanto ao comprimento máximo com auxílio de paquímetro ou quando menores que $1 \mathrm{~mm}$ medidos sob estereomicroscópio.

$\mathrm{Na}$ Laguna dos Patos coletas qualitativas foram feitas na praia arenosa com juncos junto à cidade de Arambaré, e em raízes de aguapé na cidade de São Lourenço do Sul, junto à desembocadura do rio de mesmo nome (Fig. 1).

Espécimes das amostras qualitativas foram triados em laboratório, colocados em água do ambiente, acrescentandose cristais de mentol. Após anestesia, foram fixados em formalina a 5\% e preservados em álcool a 70\%.

Pequeno aglomerado de $L$. fortunei formado por espécimes de 0,5 a 2,5 cm, foi colocado em aquário $(30 \times 17 \times 20 \mathrm{~cm}) \mathrm{com}$ aerizador comum, e os animais alimentados semanalmente, durante um ano, com um coquetel de algas vivas cultivadas pelo Laboratório de Fitoplâncton do Instituto de Biociências da PUCRS.

Os exemplares coletados no Delta do Jacuí foram incluídos na coleção malacológica do Museu de Ciências Naturais da Fundação Zoobotânica do Rio Grande do Sul (FZB-RS) (MCN 35016, 35020, 35044, 35048, 35052-35054, 35059, 35086, $35170,35238)$. Depositados na coleção malacológica do Museu 
Tabela I. Número de indivíduos de Limnoperna fortunei por grama de raiz em Eichhornia azurea (aguapé-de-baraço) e (*) E. crassipes (aguapé), coletados no Delta do Jacuí, Rio Grande do Sul, municípios de (1) Porto Alegre, (2) Triunfo e (3) Eldorado do Sul; amplitude de comprimento das conchas e médias.

\begin{tabular}{|c|c|c|c|c|c|}
\hline Datas das coletas & Localidades & $\begin{array}{l}\text { Número de } \\
\text { indivíduos }\end{array}$ & $\begin{array}{l}\text { Comprimento mínimo, } \\
\text { máximo e (média) (mm) }\end{array}$ & $\begin{array}{l}\text { Peso seco das } \\
\text { raízes }(\mathrm{g})\end{array}$ & Indivíduos/grama de raiz \\
\hline 24.XI.1998 & Ilha do Chico Inglês ${ }^{1}$ & 1 & 1 & 08,9523 & 0,11 \\
\hline 01.XII.1998 & Canal da Pintada ${ }^{1}$ & 2 & $1,0-1,8$ & 14,8779 & 0,13 \\
\hline 12.I.1999 & Ilha do Oliveira ${ }^{1}$ & 1 & 4,2 & 25,7426 & 0,04 \\
\hline 19.III.1999 & Canal Formoso ${ }^{1}$ & 1 & 11,8 & 10,9372 & 0,09 \\
\hline 14.VI.1999 & Saco da Pólvora ${ }^{1}$ & 3 & $8,8-14,5(12,5)$ & 20,9230 & 0,14 \\
\hline 05.1 .2000 & Canal da COPESUL ${ }^{2}$ & $265+7$ valvas & $0,35-11,5(2,14)$ & 29,7063 & 8,92 \\
\hline 11.1 .2000 & Ilha do Serafim ${ }^{1}$ & 12 & $0,8-9,7(4,28)$ & 09,7016 & 1,24 \\
\hline 18.1 .2000 & Canal Maria Conga ${ }^{1}$ & 29 & $0,9-10,2(2,28)$ & 20,4581 & 1,42 \\
\hline 18.I.2000 & Saco Ponta São Roque ${ }^{3}$ & 13 & $4,4-11,5(8,06)$ & 36,2672 & 0,36 \\
\hline 18.1 .2000 & Canal da Pintada ${ }^{1}$ & 4 & $1,0-2,3$ & 23,3200 & 0,17 \\
\hline 18.1 .2000 & Canal das Balseiras ${ }^{1}$ & 1 & 13,3 & $02,6831^{*}$ & $0,37^{*}$ \\
\hline
\end{tabular}

de Ciências e Tecnologia da PUCRS estão os espécimes de $L$. fortunei amostrados: em rizomas de junco (MCP 7105, 7108, 7157, 7158, 7220, 7226, 7233, 7719, 7723, 7728, 7729, 7732, $7739,7753,8137,8144,8154,8172,8175,8179,8184,8185$, $8203,8214,8841$ ); em troncos cortados de sarandi (MCP 6326, $7107,7109,7111,7219,7234,7635-7641)$; fixos sobre moluscos da fauna nativa e exótica (MCP 6323-6325, 7065, 7110, 7212, 7214, 7222, 7223, 7225); no interior dos poços de sucção da água para o abastecimento da cidade de Porto Alegre, doados pelo DMAE (MCP 7215, 05.IX.2000, 79 exs, MCP 7216, 06.IX. 2000, 236 exs, Veleiros do Sul, Porto Alegre, RS, Brasil) e na Laguna dos Patos, nas localidades de Arambaré e São Lourenço do Sul (MCP 7655, X.2000, 3 exs; MCP 7718, I.2001, 3 exs).

\section{RESULTADOS}

Coletas em raízes de aguapé-de-baraço, em novembro e dezembro de 1998, revelaram pela primeira vez, exemplares de L. fortunei, no Delta do Jacuí (Tab. I). Os primeiros registros do mexilhão-dourado são de indivíduos isolados correspondendo a menos de 1 ind./g de raiz, e de tamanho máximo de $1,8 \mathrm{~mm}$ de comprimento. No ano de 1999 , a densidade sobre as raízes de $E$. azurea continuou baixa, porém os bivalves apresentaram comprimento de até $14,5 \mathrm{~mm}$. Em janeiro de 2000 , as densidades eram relativamente baixas sobre $E$. azurea, exceto nos aguapés-de-baraço provenientes do canal da COPESUL, onde se registrou cerca de 9 ind./g. Nesse local, observou-se também, maior variação nas medidas das conchas, com indivíduos de 0,35 a $13,5 \mathrm{~mm}$ de comprimento.

As primeiras amostragens realizadas em janeiro de 1999 ao sul do Lago Guaíba, resultaram em mexilhões de até $8 \mathrm{~mm}$ de comprimento e geralmente isolados. Espécimes com comprimento máximo de $2,6 \mathrm{~cm}$ foram encontrados a partir das coletas do dia 19.X.1999.

Nos rizomas de junco (Tab. II, Fig. 2) a densidade máxima de L. fortunei foi de 27.275 ind. $/ \mathrm{m}^{2}$ em abril de 2000 , um ano e cinco meses após o primeiro registro da espécie no Lago Guaíba. A densidade máxima, em 29 de novembro, decorridos dois anos do primeiro registro da espécie no Lago Guaíba, sobre rizomas de juncos, foi de 62.100 ind. $/ \mathrm{m}^{2}$. Em 2001, terceiro ano, as densidades máximas aumentaram em janeiro e fevereiro para 143.500 e 102.800 ind. $/ \mathrm{m}^{2}$, respectivamente, diminuindo gradativamente de março a abril, com novo aumento em maio e agosto, seguindo declínio com pequenas flutuações até dezembro desse ano. No período de janeiro a julho de 2001 o declínio na densidade máxima da população acompanha a queda de temperatura do ar e da água. No entanto, no período subseqüente, de agosto a dezembro de 2001, a temperatura se eleva gradativamente, mas a população decresce, evidenciando pequenos picos em agosto, outubro e início de dezembro, que não alcançam as densidades obtidas no início do ano.

Nos troncos cortados de sarandi (Tab. III) a quantidade de espécimes de $L$. fortunei ficou limitada inicialmente ao tamanho das fissuras ou concavidades destes. A densidade máxima foi de 830 ind. $/ \mathrm{m}^{2}$ em janeiro de 1999. Ao final do mesmo ano a densidade não havia aumentado consideravelmente e os mitilídeos ainda encontravam-se restritos ao tamanho das fissuras e das concavidades. Um ano depois, constatou-se a densidade máxima de 33.573 ind. $/ \mathrm{m}^{2}$. Os bivalves foram encontrados formando agregações que ultrapassavam os limites iniciais das reentrâncias, circundando o substrato.

A partir do segundo ano da constatação de L. fortunei no Lago Guaíba, ou seja, em setembro de 2000, registraram-se os primeiros casos de macrofouling na região, causando entupimento em poços de captação de água para abastecimento 
Tabela II. Número de indivíduos de Limnoperna fortunei por $\mathrm{m}^{2}$ sobre rizomas de Scirpus californicus (C.A. Mey.) Steud. (junco), coletados no Lago Guaíba, Praia das Pombas e $\left(^{*}\right)$ Vila de Itapuã, município de Viamão, Rio Grande do Sul, utilizando-se amostradores tridimensionais com base de $10 \times 10 \mathrm{~cm}$. A temperatura da água e do ar foi medida a partir de 17.I.2001.

\begin{tabular}{|c|c|c|c|c|}
\hline $\begin{array}{l}\text { Datas das } \\
\text { coletas }\end{array}$ & $\mathrm{N}^{\circ}$ de ind. & Ind. $/ \mathrm{m}^{2}$ & $\begin{array}{c}\text { Temperatura } \\
\text { do ar }\left({ }^{\circ} \mathrm{C}\right)\end{array}$ & $\begin{array}{l}\text { Temperatura } \\
\text { da água }\left({ }^{\circ} \mathrm{C}\right)\end{array}$ \\
\hline 22.XI.1999* & 6 & & & \\
\hline 22.XI.1999 & 3 & & & \\
\hline 06.IV.2000 & 1091 & 27.275 & & \\
\hline 14.VI.2000 & 571 & 24.325 & & \\
\hline 07.XI.2000 & 434 & 43.400 & & \\
\hline 29.XI.2000 & 621 & 62.100 & & \\
\hline 18.XII.2000 & 342 & 34.200 & & \\
\hline 17.I.2001 & 1435 & 143.500 & 30,0 & 28,0 \\
\hline 04.II.2001 & 1028 & 102.800 & 22,5 & 27,0 \\
\hline 08.III.2001 & 929 & 92.900 & 28,0 & 27,5 \\
\hline 29.III.2001 & 626 & 62.600 & 23,0 & 26,0 \\
\hline 11.IV.2001 & 637 & 63.700 & 19,5 & 24,0 \\
\hline 09.V.2001 & 747 & 74.700 & 19,0 & 18,5 \\
\hline 24.V.2001 & 625 & 62.500 & 19,5 & 19,0 \\
\hline 08.VI.2001 & 614 & 61.400 & 21,0 & 22,0 \\
\hline 27.VI.2001 & 511 & 51.100 & 13,0 & 14,0 \\
\hline 13.VII.2001 & 593 & 59.300 & 14,0 & 15,0 \\
\hline 02.VIII.2001 & 661 & 66.100 & 21,0 & 18,0 \\
\hline 29.VIII.2001 & 787 & 78.700 & 18,0 & 19,0 \\
\hline 11.IX.2001 & 379 & 37.900 & 15,0 & 16,0 \\
\hline 29.IX.2001 & 456 & 45.600 & 19,5 & 21,0 \\
\hline 11.X.2001 & 413 & 41.300 & 25,0 & 23,5 \\
\hline 11.X.2001 & 542 & 54.200 & 25,0 & 23,5 \\
\hline 14.XI.2001 & 303 & 30.300 & 23,0 & 26,0 \\
\hline 12.XII.2001 & 424 & 42.400 & 26,0 & 25,5 \\
\hline
\end{tabular}

da cidade de Porto Alegre, próximos às localidades de Belém Novo $\left(30^{\circ} 15^{\prime} \mathrm{S}, 51^{\circ} 05 \mathrm{~W}\right)$ e do Clube Náutico Veleiros do Sul $\left(30^{\circ} 05^{\prime} \mathrm{S}, 51^{\circ} 15^{\prime} \mathrm{W}\right)$ e em dezembro de 2000 , o entupimento de grades protetoras, tanques, trocadores de calor e tubulações para tomadas de água da indústria Klabin-Riocell, no município de Guaíba. Segundo informação do mecânico do Clube Veleiros
Densidades máximas de Limnoperna fortunei no Guaíba, período de 1999 a 2001.

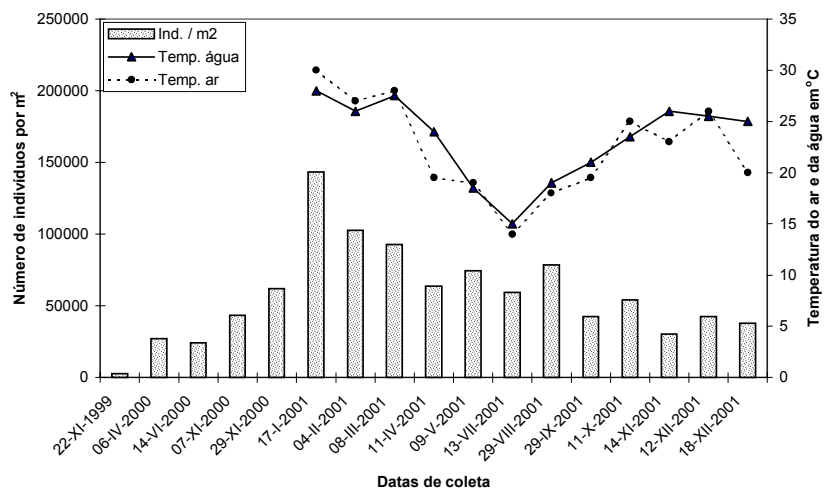

Figura 2. Número máximo de indivíduos por $\mathrm{m}^{2}$ de populações de Limnoperna fortunei (Dunker, 1857) sobre rizomas de Scirpus californicus (C.A. Mey.) Steud. (junco), amostrados na praia do camping das Pombas, Viamão, no período de novembro de 1999 a dezembro de 2001, e flutuações da temperatura do ar e da água.

Tabela III. Número de indivíduos de Limnoperna fortunei por $\mathrm{m}^{2}$ sobre troncos cortados de Cephalanthus glabratus (Spreng.) K. Schum.(sarandi), na Vila de Itapuã, município de Viamão, Rio Grande do Sul, contidos em uma amostra de $20 \mathrm{~cm}$ de comprimento por 12 $\mathrm{cm}$ de largura e médias anuais dos ind. $/ \mathrm{m}^{2}$.

\begin{tabular}{lcrc}
\hline Datas das coletas & $\mathrm{N}^{\circ}$ de ind. & Ind. $/ \mathrm{m}^{2}$ & $\begin{array}{c}\text { Médias anuais } \\
\text { dos ind. } / \mathrm{m}^{2}\end{array}$ \\
\hline 19.I.1999 & 20 & 830 & \\
19.X.1999 & 14 & 581 & \\
22.XI.1999 & 13 & 539 & \\
14.XII.1999 & 02 & 83 & \\
14.XII.1999 & 57 & 2.365 & \\
1999 & & & \\
18.XII.2000 & 462 & 19.173 \\
18.XII.2000 & 776 & 32.204 \\
18.XII.2000 & 281 & 11.661 \\
18.XII.2000 & 276 & 11.454 \\
18.XII.2000 & 809 & 33.573 \\
18.XII.2000 & 713 & 29.589 \\
18.XII.2000 & 447 & 18.550 \\
18.XII.2000 & 642 & 26.643 \\
2000 & & & 22.856 \\
\hline & & & \\
\hline
\end{tabular}

Revista Brasileira de Zoologia 20 (1): 75-84, março 2003 
Tabela IV. Número de indivíduos de Limnoperna fortunei fixos em cada espécime da malacofauna nativa e exótica coletados no Lago Guaíba, Rio Grande do Sul.

\begin{tabular}{|c|c|c|c|}
\hline Localidades & Datas das coletas & Espécies utilizadas como substrato para fixação & $N^{\circ}$ de ind. L. fortunei \\
\hline \multirow[t]{5}{*}{ Vila de Itapuã } & 19.I.1999 & Anodontites trapesialis (Lamarck,1819) & 3 \\
\hline & & Diplodon koseritzi (Clessin, 1888) & 1 \\
\hline & & Corbicula fluminea (Müller, 1774) & 1 \\
\hline & $07 . X I .2000$ & Pomacea canaliculata (Lamarck, 1822) & 1 \\
\hline & & Diplodon sp. & 3 \\
\hline \multirow[t]{6}{*}{ Praia das Pombas } & 19.I.1999 & Anodontites trapezeus (Spix, 1827) & 1 \\
\hline & 22.XI.1999 & Leila blainvilliana (Lea, 1834) & 1 \\
\hline & & Anodontites trapezeus (Spix, 1827) & 2 \\
\hline & 14.VI.2000 & Corbicula fluminea (Müller, 1774) junto com Diplodon koseritzi & 280 \\
\hline & & Corbicula fluminea & 172 \\
\hline & $07 . X I .2000$ & Corbicula fluminea & 9 \\
\hline
\end{tabular}

do Sul, em apenas três meses a partir do lançamento do barco na água, podem ocorrer a queima ou baixo rendimento dos motores de barcos, pelo entupimento de encanamentos de refrigeração e ou incrustações sobre hélices, ocasionando grandes prejuízos aos clubes náuticos.

No terceiro ano foram observadas densas incrustações sobre troncos novos e ramificações submersas de sarandi, sobre as pedras dos pontais, dos molhes, marinas e trapiches do Lago Guaíba, como também sob barcos cujos cascos haviam sido pintados com tintas anti-incrustantes. Segundo informação dos pescadores da Praia do Veludo, no Lago Guaíba, as incrustações se formam nos barcos em apenas nove meses (Fig.11), mesmo após pintura especial. Válvulas de retenção das bombas captadoras de água do lago (Fig. 9) também entupiram em três meses, a partir do início de sua utilização.

Testes de colonização com tijolos perfurados não permitiram a obtenção de resultados regulares devido ao roubo de parte do material em janeiro e fevereiro de 2001. Tijolo reencontrado (Fig. 10) nos permitiu constatar que no período de 102 dias, no verão (7.XI.2000 a 14.II.2001), houve obstrução parcial das perfurações com $3 \mathrm{~cm}$ de diâmetro e total daquelas com $1 \mathrm{~cm}$ de diâmetro.

Limnoperna fortunei fixa-se preferencialmente a substratos firmes com rugosidades como os rizomas de junco, nas concavidades de troncos, sobre bivalves de água doce e mais raramente em raízes de aguapé (Tabs. I-IV). Superfícies muito lisas como os talos dos juncos, ou troncos e caules sem concavidades ou ramificações, não estavam colonizados por $L$. fortunei nesses primeiros dois anos de ocupação.

Nas áreas de juncais, os primeiros registros de L. fortunei foram nos rizomas não cobertos por areia (Fig. 3), que se alinham nos limites mais internos dos juncais para dentro do Lago Guaíba, em profundidades que variam de 80 a $110 \mathrm{~cm}$. A partir do segundo ano de instalação, L. fortunei passou a formar grandes adensamentos sobre os rizomas de juncos, englobando também porções de areia (Fig. 4). Conseqüentemente, os adensamentos aumentaram de tamanho, formando massas volumosas. No terceiro ano observou-se que alguns aglomerados se tangenciaram e se anastomosaram, formando verdadeiros tapetes espessos dentro dos juncais, prolongandose e cobrindo também porções arenosas internas e periféricas. Percebeu-se que a partir da formação dos grandes aglomerados de $L$. fortunei, os juncos passaram a se desenvolver de forma esparsa, apresentando também grandes lacunas ocupadas por mexilhões-dourados. Constatou-se uma perda de $6 \%$ do juncal da Praia das Pombas no período de um ano entre dezembro de 2000 e novembro de 2001.

Encontrou-se $L$. fortunei fixa sobre toda a superfície da concha de bivalves (Figs.5-7, Tab. IV), inclusive junto à abertura inalante de Corbicula fluminea (Fig. 6), Diplodon koseritzi e Leila blainvilliana (Lea, 1834) (Fig. 7). A quantidade de L. fortunei envolvendo a concha de um único espécime de Corbicula fluminea foi de 172 indivíduos. Um exemplar de $C$. fluminea justaposto a um de Diplodon koseritzi, foram encontrados envolvidos quase completamente por 280 exemplares de $L$. fortunei. Em Leila blainvilliana constatou-se um mexilhão preso também sobre as partes moles, junto ao sifão exalante, impedindo o fechamento de suas valvas (Fig. 7) que na tentativa de fechamento da concha teve as bordas danificadas, sem prejuízo à concha do epizonte. Limnoperna fortunei também foi observado sobre o gastrópode Pomacea canaliculata (Lamarck, 1822), na concavidade umbilical (Fig. 8), impedindo-o de fechar totalmente a concha com seu opérculo.

\section{DISCUSSÃO}

As coletas de $L$. fortunei no Delta do Jacuí, em novembro e dezembro de 1998, são anteriores aos da notificação de MANSUR et al. (1999), que data os primeiros registros para janeiro de 1999. 

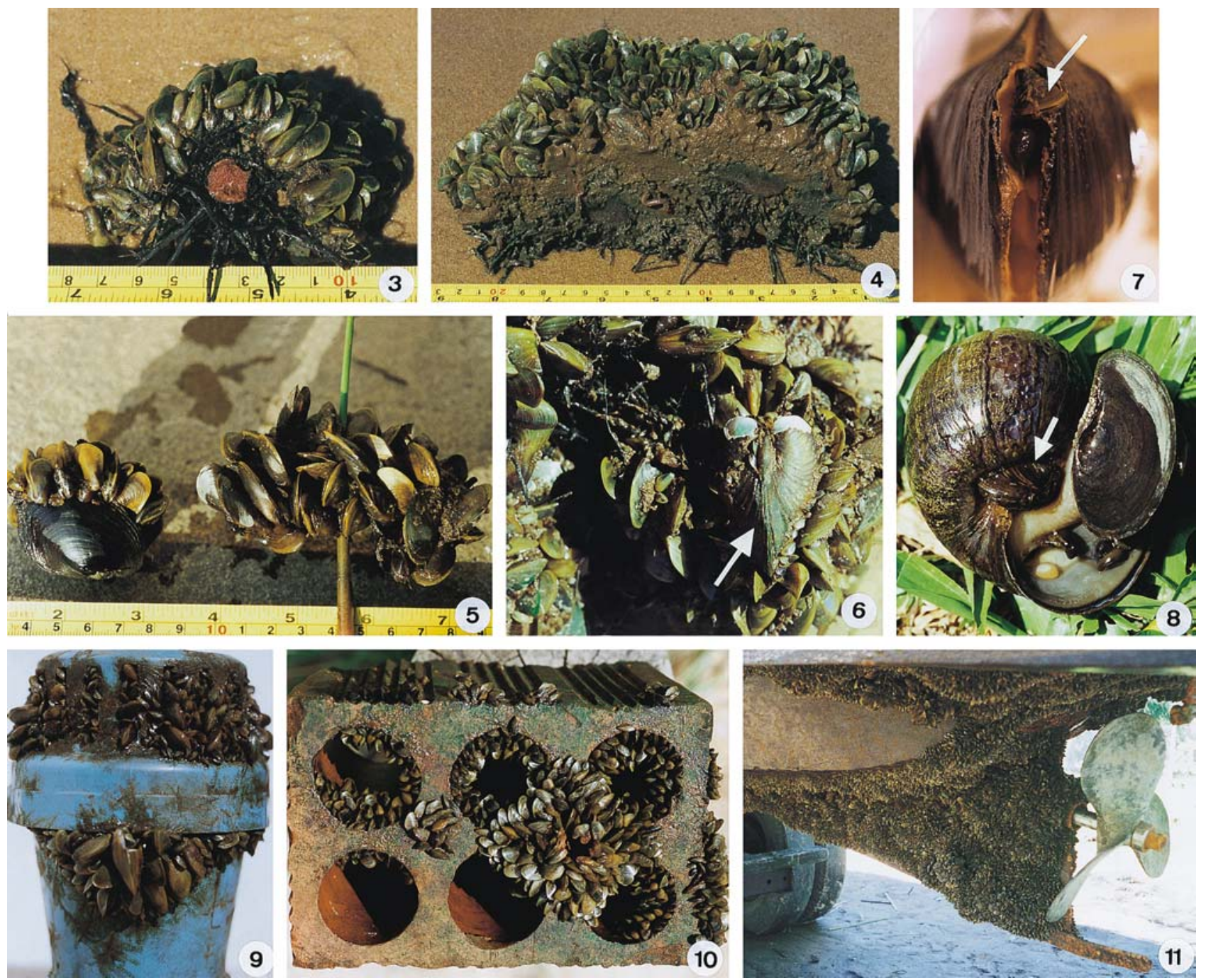

Figuras 3-11. $(3,4)$ Perfil de um corte transversal do rizoma de Scirpus californicus (C. A. Mey.) Steud (junco), evidenciando adensamento de Limnoperna fortunei (Dunker, 1857) (3) no primeiro ano de invasão e (4) depois de um ano de fixação; (5) Diplodon deceptus Simpson, 1914 sensu Ortman, 1921, parcialmente coberto pelo mexilhão-dourado e à direita, haste do junco estrangulada pelo bivalve; (6) Corbicula fluminea (Müller, 1774) (seta), parcialmente coberta por exemplares de L. fortunei grandes e jovens abrigados entre os adultos; (7) Leila blainvilliana (Lea, 1834) apresentando as valvas parcialmente danificadas pelo L. fortunei e com exemplar do mexilhãodourado fixo às suas partes moles, junto à abertura exalante (seta); (8) Pomacea canaliculata (Lamarck, 1822) com espécime de L. fortunei (seta), fixo na cavidade umbilical, impedindo o fechamento da concha pelo opérculo; (9) Exemplo de macrofouling em válvula de retenção de bomba captadora de água do Lago Guaíba, Praia do Veludo, bloqueada pelo mexilhão-dourado após três meses de uso dentro d'água; (10) Tijolo vazado com dimensões de 14 × 10,5 ×9,5 cm, retirado da Praia das Pombas, Lago Guaíba, após 102 dias de imersão (7.XI.2000 a 14.II.2001); (11) Barco retirado da Praia do Veludo, Lago Guaíba, em outubro de 2001, com incrustações formadas por L. fortunei em menos de 9 meses a partir do lançamento do barco na água. 
A constatação de mexilhões pequenos e isolados ou no máximo formando agrupamentos de poucos exemplares, nas primeiras amostragens no Delta do Jacuí e no Lago Guaíba, coincidem com as observações de DaRRIGRAN \& PASTORINo (1993) para os primeiros espécimes coletados no Rio da Prata em setembro de 1991.

O registro de L. fortunei no Rio da Prata foi facilitado pelo fato de muitas margens apresentarem rochas aplanadas que ficam a descoberto quando a maré está baixa. O Lago Guaíba não está sujeito a regime de marés, sendo que a maioria dos componentes da fauna aquática permanece submersa, oculta da visão humana. Limnoperna fortunei foi inicialmente amostrado durante as coletas das raízes de aguapé, bivalves (Corbiculidae ou Unionoida), pedaços de troncos ou outros objetos facilmente removíveis do fundo. Somente a partir de novembro de 1999 foram observados espécimes de $L$. fortunei sobre os rizomas de juncos. É muito provável que o mexilhãodourado já estivesse colonizando os rizomas de junco, desde janeiro de 1999, quando foi amostrado pela primeira vez ao sul do Lago Guaíba. Esta colonização não foi percebida, inicialmente, apesar do junco ser abundante e característico da região. Isto se deve ao fato dos indivíduos de $L$. fortunei apresentarem, inicialmente, pequenas dimensões que o tornaram imperceptíveis ao tato com auxílio dos pés. Soma-se também o fato da dificuldade de remover os rizomas do substrato.

Em abril de 2000 apareceram as primeiras grandes aglomerações sobre rizomas de junco no Lago Guaíba. Dois meses depois, houve um decréscimo que pode ser atribuído ao início do inverno e do período de chuvas. Em novembro de 2000 apareceram as aglomerações sobre rizomas com o dobro de indivíduos e a densidade máxima de 62.100 ind. $/ \mathrm{m}^{2}$, como também os primeiros registros de macrofouling. Este período de aproximadamente dois anos, para a formação das primeiras grandes aglomerações de L. fortunei no Lago Guaíba, mostra que a ocupação foi um pouco menos acelerada que no Rio da Prata. Darrigran \& Pastorino (1993) e Darrigran (1995) obtiveram densidades semelhantes já no final do primeiro ano. DarRigran \& PAStorino (1993) encontraram, nove meses depois do primeiro registro de L fortunei no Rio da Prata, uma densidade de 31.227 ind. $/ \mathrm{m}^{2}$. Houve um decréscimo em agosto do mesmo ano, atribuído a um aumento da salinidade no Rio da Prata. A densidade aumentou para 42.000 ind. $/ \mathrm{m}^{2}$ em fevereiro de 1993 e em maio do mesmo ano, elevou-se para 82.151 ind. $/ \mathrm{m}^{2}$, mais do que o dobro encontrado no ano anterior.

Só a partir de janeiro de 2001 a densidade máxima passa de 100.000 ind. $/ \mathrm{m}^{2}$ no Lago Guaíba. Nestes meses de verão foi observado um grande número de mexilhões com poucos milímetros de comprimento, fixos sobre e entre os exemplares maiores que $1 \mathrm{~cm}$, provavelmente pertencentes a gerações anteriores, razão da maior densidade encontrada. O decréscimo, a partir de março, deve-se à facilidade que os bivalves apresentam em desprender o bisso do substrato e se deslocarem para outras superfícies. URYu et al. (1996) realizaram uma série de experimentos em laboratório, demonstrando a tendência gregária, a capacidade de soltar o bisso, tipos de deslocamento, formação de novos assentamentos e tigmotactismo positivo, principalmente em exemplares de $L$. fortunei menores de 15 $\mathrm{mm}$. Segundo esses autores, a presença de exemplares maiores estimula os menores a secretarem o bisso, e que estes movimentos e comportamentos poderiam significar uma resposta adaptativa relacionada à predação e ao deslocamento por ondas e correnteza da água.

Observou-se que os espécimes menores costumam fixarse juntos às laterais das agregações e entre os indivíduos maiores (Fig. 6), formando aglomerados extremamente compactos, fato que provavelmente impede a ação de eventuais predadores. À medida que crescem, podem se deslocar, buscando outras superfícies. Esta capacidade dos bivalves se desprenderem à procura de outras superfícies, foi constatada em mexilhões colocados em aquário no laboratório. Geralmente estes formaram novos aglomerados nas áreas mais oxigenadas.

A fixação inicial de $L$. fortunei nos rizomas e raízes dos juncos, situados mais internamente no lago, deve-se provavelmente ao fato das larvas do mexilhão-dourado terem encontrado aí o primeiro local favorável à fixação. Os rizomas de juncos não são lisos porém envoltos por raízes fasciculadas (Fig. 3), que oferecem proteção e maior superfície de aderência às larvas. Percebeu-se que nas margens mais externas e centrais dos juncais, os rizomas ficam cobertos por uma camada de aproximadamente $10 \mathrm{~cm}$ de areia, não permitindo que os mitilídeos se fixem. No limite mais distante da praia, onde os juncais ficam mais submersos na água, os rizomas apresentam-se menos cobertos pela areia e muitas vezes com o rizoma e suas raízes totalmente expostas no fundo, favorecendo a fixação do bivalve. Acredita-se que nesta área limítrofe dos juncais, a areia seria removida pela ação das ondas provocadas pelos ventos. Os juncos formam verdadeiras barreiras contra os ventos, permitindo uma maior deposição de areia e matéria orgânica, protegendo as margens do lago contra erosão. Observou-se que em algumas áreas junto ao camping das Pombas e Vila de Itapuã houve a remoção, pelo homem, dos talos dos juncos, sem a retirada dos rizomas. Sem a proteção dos talos, as raízes ficaram rapidamente expostas dentro d'água e $L$. fortunei formou em pouco tempo aglomerados sobre os rizomas, em áreas com menos de $50 \mathrm{~cm}$ de profundidade da superfície d'água.

Uma recente redução dos juncais foi constatada em certas regiões ao sul do Lago Guaíba, fato que pode estar associado à invasão da espécie e sua preferência pelos rizomas de junco. É nesta região do lago onde existem os maiores juncais. É possível que o desaparecimento dos juncais no entorno da Ilha dos Juncos, próximo ao estreito de Itapuã, onde o lago se comunica com a Laguna dos Patos, deva-se ao assentamento de populações de L. fortunei. É provável que os grandes aglomerados do mexilhão-dourado sobre os rizomas, causem o sufocamento e apodrecimento destes.

No camping das Pombas foi possível evidenciar que no local onde foram cortados os talos de juncos, os exemplares de L. fortunei assentaram-se, e em pouco tempo envolveram os rizomas, formando massas volumosas, tornando-se raro o surgimento e crescimento de novos talos. Constatou-se também que os mitilídeos envolvem o broto e talo novo, estrangulandoo pela base (Fig. 5). O talo cresce, em alguns casos, elevando o aglomerado, mas pende para o lado pelo peso dos moluscos, impedindo seu crescimento vertical.

Sabe-se que $L$. fortunei altera a composição do bentos atraindo certas espécies e afastando outras (DARRIGRAN et al. 1998), com impactos sobre bivalves nativos e invasores como a Corbicula fluminea (DarRigran 2000). Por ser filtrador ativo, acumula grande quantidade de pseudofezes que possibilitam o desenvolvimento de bactérias e fungos. A fixação de larvas do mexilhão-dourado junto às aberturas dos bivalves, que, após 
crescerem (Figs. 5, 6), sufocam o molusco, coincidiu com o que foi registrado para os bivalves nativos da Bacia do Rio da Prata (Darrigran 2000, Darrigran \& Ezcurra de Drago 2000b). O caso citado de L. fortunei, epizóica da região umbilical de Pomacea canaliculata, impediu o fechamento do opérculo do gastrópode (Fig. 8). O gastrópode e os bivalves tornaram-se, portanto, vulneráveis aos seus predadores. Há riscos de aceleração da extinção das espécies mais raras de bivalves como Leila blainvilliana e Castalia martensi (Ihering, 1891) e do bivalve endêmico da Bacia da Laguna dos Patos, Diplodon koseritzi que vive entre os rizomas dos juncos, substrato preferencial da espécie invasora.

\section{AGRADECIMENTOS}

Ao Sr. Aquiles da Rosa de Carvalho, mecânico do Clube Náutico Veleiros do Sul, pelas informações fornecidas e ao Sr. Bruno Gonzalez Torres, pela permissão de coleta em sua propriedade, o camping das Pombas, Itapuã. Ao Sr. Nei de Souza Antunes, Presidente da Associação dos Pescadores (APESCA), com sede na Praia do Veludo, pelas facilidades oferecidas para coleta e fotografia do material e ao Sr. Fernando da Luz, motorista, por ter-nos conduzido aos locais de coleta durante o período do trabalho. Às biólogas Maria Mercedes Bendati, Diretora Científica do DMAE, pelo material cedido para o estudo, e Carmem Suzana Martins de Freitas (PUCRS) pela identificação das plantas. Aos consultores pelas valiosas críticas e sugestões. À Agência Nacional Promoción Científica y Tecnológica, Argentina, pelo apoio financeiro à parte do projeto (PICT98 N 01-03453).

\section{REFERÊNCIAS BIBLIOGRÁFICAS}

BonetTo, A.A. \& M.C.D. Mansur. 1970. Las naiades de la cuenca del Guaíba. Acta Zoologica Lilloana, Tucumán, 27: 241260.

Callil, C.T. \& M.C.D. Mansur. 2002. Corbiculidae (Mollusca, Bivalvia) in Pantanal of Mato Grosso, high Paraguay Basin, Brazil: distribution and population density. Amazoniana, Kiel, 17 (1/2): 1-15.

DARRIGRAN, G. 1995. Limnoperna fortunei: ¿Um problema para los sistemas naturales de água dulce del Mercosur? Revista Museo La Plata, La Plata, 1 (5): 85-87.

2000. Invasive freshwater bivalves of the Neotropical Region. Dreissena, New York, 11 (2): 7-13.

Darrigran, G. \& I. Ezcurra de Drago. 2000a. Distribucion de Limnoperna fortunei (Dunker, 1857) (Mytilidae), en la cuenca del Plata, Region Neotropical. Medio Ambiente, Buenos Aires, 13 (2): 75-79.

. 2000b. Invasion of the exotic freshwater mussel Limnoperna fortunei (Dunker, 1857) (Bivalvia: Mytilidae) in South America. The Nautilus, Sanibel, 114 (2): 69-73.

Darrigran, G. \& G. Pastorino. 1993. Bivalvos invasores en el Rio de La Plata, Argentina. Comunicaciones de la Sociedad Malacologica del Uruguay, Montevideo, 7 (64/65): 309313.

. 1995. The recent introduction of a freshwater asiatic bivalve Limnoperna fortunei (Mytilidae) into South America. The Veliger, Berkeley, 32 (2): 171-175.

Darrigran, G.; S.M. Martin; B. Gullo \& L. Armendariz. 1998.
Macroinvertebrate associated with Limnoperna fortunei (Dunker, 1857) (Bivalvia, Mytilidae) in Rio de la Plata, Argentina. Hydrobiologia, Dordrecht, 367: 223-230.

Darrigran, G.; P. Penchaszadeh \& C. Damborenea. 2000. An invasion tale: Limnoperna fortunei (Dunker, 1857) (Mytilidae) in the Neotropics. In: R. Claudi (Ed.) Proceeding of the International Aquatic Nuisance Species and ZebraMussels Conference 10, Toronto, p. 219-224.

Ituarte, C. F. 1981. Primera noticia acerca de la introducción de pelecipodos asiaticos en la area rioplatense (Mollusca, Corbiculidae). Neotropica, La Plata, 27 (7): 79-82.

1994. Corbicula and Neocorbicula (Bivalvia: Corbiculidae) in the Paraná, Uruguay, and Rio de La Plata Basins. The Nautilus, Sanibel, 107 (4): 129-135.

Mansur, M.C.D. 1970. Lista dos moluscos bivalves das famílias Hyriidae e Mycetopodidae para o Estado do Rio Grande do Sul. Iheringia, Sér. Zool., Porto Alegre, (39): 33-95.

Mansur, M.C.D. \& L.M.M.P. Garces. 1988. Ocorrência e densidade de Corbicula fluminea (Müller, 1774) e Neocorbicula limosa (Maton, 1811) na Estação Ecológica do Taim e áreas adjacentes, Rio Grande do Sul, Brasil. Iheringia, Sér. Zool., Porto Alegre, (69): 99-116.

Mansur, M.C.D.; L.M.Z. Richinitti \& C.P. dos Santos. 1999. Limnoperna fortunei (Dunker, 1857) molusco bivalve invasor na bacia do Guaíba, Rio Grande do Sul, Brasil. Biociências, Porto Alegre, 7 (2): 147-149.

Mansur, M.C.D.; R.M. Valer \& N.C.M. Aires. 1994. Distribuição e preferências ambientais dos moluscos bivalves do açude do Parque de Proteção Ambiental da COPESUL, Município de Triunfo, Rio Grande do Sul. Biociências, Porto Alegre, 2 (1): $27-45$.

Morton, B. 1979. Corbicula in Asia. In: J.C. Briton; J.S. Mattice; C.E. Murphy \& L.W. Newland (Eds). Proceedings of the First Internacional Corbicula Symposium, Fort Worth, Christian Univ. Research Foundation, p. 15-38.

Neves, R.J.; A.E. Bogan; J.D. Williams; S.A. Ahlstedt \& P.W. Hartfield. 1997. Status of aquatic mollusks in the Southeastern United States: A downward spiral of diversity, p. 43-85. In: G.E. Benz \& D.E. Collins (Eds). Aquatic Fauna in Peril: The southeastern perspective. Decatur, Southeast Aquatic Research Institut. Special Publication 1, 554p.

Niencheski, L.F.; O.O. Möller Jr.; C. Odebrecht \& G. Fillmann. 1988. Distribuição espacial de alguns parâmetros físicos e químicos na Lagoa do Patos-Porto Alegre a Rio Grande, RS. Acta Limnologica Brasiliensia, São Paulo, 11: 79-97.

Parodiz, J.J. \& L. Hennings. 1965. The Neocorbicula (Mollusca, Pelecypoda) of the Parana-Uruguay basin, South America. Annals of the Carnegie Museum, Pittsburg, 38 (3): 69-96.

Pastorino, G.; G. Darrigran; S. Martin \& L. Lunaschi. 1993. Limnoperna fortunei (Dunker, 1857) (Mytilidae), nuevo bivalvo invasor en aguas del río de La Plata. Neotropica, La Plata, 39 (101/102): 34.

Pereira, D.; I.L. Veitenheimer-Mendes; M.C.D. Mansur \& M.C.P. DA SiLVA. 2000. Malacofauna límnica do sistema de irrigação da microbacia do Arroio Capivara, Triunfo, RS, Brasil. Biociências, Porto Alegre, 8 (1): 147-157.

Scarabino, F. \& A. Masello. 1996. Dos moluscos interessantes encontrados em um sector de la costa oeste de Montevideo: Parodizia uruguayensis (Gastropoda) y Limnoperna fortunei 
(Bivalvia). In: Conferência del Centro Internacional de Investigaciones para el Desarrollo (CIID/IDRC), Montevideo, Resumos, p. 1.

SCARAbino, F. \& M. Verde. 1994. Limnoperna fortunei (Dunker, 1857) en la costa uruguaya del Rio de la Plata (Bivalvia, Mytilidae). Comunicaciones de la Sociedad Malacologica del Uruguay, Montevideo, 7 (66/67): 374-376.

Schwarzbold, A.; O.F.M. Fonseca \& T. Guerra. 1986. Aspectos limnológicos do Saco de Tapes, Laguna dos Patos. Acta Limnologica Brasiliensia, São Paulo, 1: 89-102.

URYu, Y.; K. IWASAKI \& M. HINQUE. 1996. Laboratory experiments on behavior and movement of a freshwater mussel, Limnoperna fortunei (Dunker). The Journal of Molluscan
Studies, London, 62: 327-341.

Veitenheimer-Mendes, I.L. 1981. Corbicula manilensis (Philippi, 1844) molusco asiático, na bacia do Jacuí e do Guaíba, Rio Grande do Sul, Brasil (Bivalvia, Corbiculidae). Iheringia, Sér. Zool., Porto Alegre, (60): 63-74.

Vieira, E.F. \& S.R.S. RANGEL. 1988. Planície Costeira do Rio Grande do Sul: Geografia física, vegetação e dinâmica sócio-demográfica. Porto Alegre, Sagra, 256p.

Volkmer-Ribeiro, C.; B. Mothes-de-Moraes; R. de-Rosa-Barbosa; M.C.D. Mansur \& I.L. Veitenheimer-Mendes. 1984. Um estudo do bentos em raízes de Eichhornia azurea (Sw.) Kunth, do curso inferior de um rio subtropical sul-americano. Revista Brasileira de Biologia, Rio de Janeiro, 44 (2): 125-132.

Recebido em 26.VIII.2002; aceito em 26.II.2003.

Revista Brasileira de Zoologia 20 (1): 75-84, março 2003 